\title{
Evaluation of night eating syndrome in individuals with and without obesity
}

\author{
Cuneyt Sutcu ${ }^{\circledR}$, Gülseren Pamuk®, Kurtuluş Ongel \\ Department of Family Medicine, Izmir Katip Celebi University, Ataturk Training and Research Hospital, Izmir, Turkey
}

\begin{abstract}
Introduction: There are publications with contrasting results on the relationship between night eating syndrome and obesity. The aim of this study was to investigate the frequency and relationship between night eating syndrome (NES) in obese and non-obese participants. Material and methods: Between 1 January 2018 and 1 May 2018, 420 people ages 18-65 years who applied to İzmir Katip Çelebi University Atatürk Training and Research Hospital Family Medicine and Endocrinology outpatient clinics for any reason enrolled in this study. Body mass index $\left(\mathrm{BMI}=\right.$ weight $[\mathrm{kg}] /$ height $\left.^{2}\left[\mathrm{~m}^{2}\right]\right)$ was calculated by measuring participants' height and weight. BMI values between 18.50 and 24.99 were normal weight, between 25.0 and 29.99 were overweight, between 30.0 and 39.99 were obese, and 40.0 and above were considered morbidly obese. Participants' sociodemographic data, the Night Eating Questionnaire (NEQ), and the Beck Depression Inventory (BDI) were administered by face-to-face interview technique.

Results: The average age of the participants was $42 \pm 13$ years and $68.6 \%$ were female. The mean body mass index (BMI) of the participants was $31.8 \pm 8.2$. The prevalence of NES was determined: $10 \%$ of the participants had NES. The higher frequency of NES in patients with morbid obesity was found to be statistically significant compared to those without morbid obesity $(\mathrm{p}<0.05)$. The mean BDS score was $23.5 \pm 10.86$ (min: 0, max: 46) in the NES group and $12.18 \pm 88.95$ (min: 0, max: 49) in the non-NES group. There was a significant difference between the two groups in terms of BDS scores $(\mathrm{p}<0.001)$.

Conclusions: Because obesity has an important place in primary health care services, it is important to know the relationship between NES and depression. Recognition of NES and consideration of planned follow-up and treatment in the applicants will help to treat obesity more effectively. (Endokrynol Pol 2021; 72 (5): 539-544)
\end{abstract}

Key words: depression; night eating syndrome; obesity

\section{Introduction}

Obesity, which is a multifactorial, complex, and largely preventable disease affecting more than a third of the world's population, occurs with the effect of biological, behavioural, and environmental factors [1]. If ongoing trends continue, it is expected that by $203020 \%$ of the world's adult population will be obese and $38 \%$ will be overweight [2]. It is known that obesity has many medical complications, increases morbidity and mortality, and decreases the quality of life [3]. Because nutritional disorders and especially diseases with metabolic components are increasing in the world, it is an important goal to fight the factors that cause the disease, which can be effective in preventing diseases and complications.

Night eating syndrome (NES) was first described by Stunkard in 1955 as a disorder characterized by anorexia in the morning, hyperphagia in the evening, and insomnia in patients with treatment-resistant obesity [4]. The prevalence of NES was first investigated in obese patients, and the incidence of NES in obese patients has been reported between $6 \%$ and $16 \%$, while it was reported that the frequency of NES ranged between $4.3 \%$ and $14 \%$ in people seeking treatment for weight loss $[5,6]$. In a study conducted with normal weight people, the frequency of NES was found to be $0.4 \%$. The prevalence of NES is reported as $1-1.5 \%$ in the adult population [7].

Contrary to these studies, the relationship of night eating with BMI and obesity was examined in another study, and it was found that night eating was more frequent in normal weight peoples than overweight and obese patients [8]. Again, Striegel-Moore et al. reported that in a study conducted by women with NES, no significant difference was found between black women with NES and black women without NES in terms of mean BMI and frequency of obesity [9]. Moreover, Lundgren et al. reported that no significant difference was found in the mean BMI between those with and without night eating [10].

The primary aim of this study is to explore the prevalence of NES in obese and non-obese individuals. The

Gülseren Pamuk, MD, Department of Family Medicine, Izmir Katip Celebi University School of Medicine,

Ataturk Education and Research Hospital, 35150, Karabaglar/Izmir, Turkey, tel: (+90) 553 6262596; e-mail: drgulpmk@gmail.com 
secondary purpose is the evaluation of the relationships between NES and obesity, depression level, and sociodemographic and lifestyle characteristics.

\section{Material and methods}

\section{Ethics statement}

The study complied with the ethical rules in the Declaration of Helsinki, and ethics committee approval was obtained from İzmir Katip Celebi University (IKKÇÜ) Non-Interventional Clinical Research Ethics Committee with the decision number 305 dated 20/12/2017. The participants were informed about the study, and written informed consent was obtained.

\section{Patients}

Patients who applied to Izmir Katip Çelebi University Atatürk Training and Research Hospital Family Medicine and Endocrine outpatient clinics between 1 January 2018 and 1 May 2018 were included in the study. All anthropometric measurements (body weight, height) of the participants were made by the same researcher to reduce the error rate. After taking off their shoes, their weight was measured with the help of a standard scale and height meter after removing excess clothing. Participants' height and weight were measured, and the body mass index (BMI = weight $[\mathrm{kg}] /$ height $^{2}[\mathrm{~m}]$ ) was calculated. Participants in the study were evaluated in 4 groups as normal weight, overweight, obese, and morbidly obese according to their BMI. Those with a BMI value between 18.50 and 24.99 were normal weight, 25.0-29.99 were overweight, 30.0-39.99 were obese, and over 40.0 were evaluated as morbidly obese [11].

Inclusion criteria of this cross-sectional study were as follows: 1) being informed about the study and obtaining consent; 2) being between 18 and 65 years old; 3 ) having the ability to communicate verbally; 4 ) having the ability to cognitively answer all questions in questionnaires. The exclusion criteria of this study were as follows: 1) refusal to participate in the study; 2) being deaf and blindness disabled; 3) pregnant and breastfeeding; 4) alcohol and substance addiction; and 5) night shift workers. The demographic data of the study population are summarized in Table 1.

\section{Clinical assessment}

An 18-question questionnaire for socio-demographic data developed by the researchers, a 16-question Night Eating Questionnaire, and a 21-question Beck Depression Inventory were applied to the participants using a face-to-face interview technique. The Sociodemographic Data Survey was a questionnaire form consisting of 18 questions prepared by the researchers including descriptive questions such as "age, gender, educational status, marital status, occupation, economic status, cohabitants, habits (smoking, alcohol), the names of their diseases, the drugs they use continuously, their physical activity status". The Night Eating Questionnaire is a scale developed in 2008 by Allison et al. The questionnaire includes questions about morning appetite and first food intake of the day, evening and night meals, food intake rate after dinner, cravings, control of night eating behaviour, difficulty falling asleep, frequency of eating at night, and awareness and mood during night meals. The total score can be between 0 and 52 . In the original study, it was reported that the positive predictive value for a score of 25 and above points was low $(40.7 \%)$, and this value increased to $72.7 \%$ for 30 and above points. In the same study, the negative predictive value for NES was found to be high $(95.2 \%$ and $94 \%$, respectively) at both cut-off points above 25 and 30 points [12]. The Turkish validity and reliability study was conducted by Atasoy et al. in 2014 [13].

The Beck Depression Inventory aims to measure the severity of depression-related symptoms in cognitive, emotional, motivational, and physical dimensions and takes into account the mental state
Table 1. Demographic data of the study population

\begin{tabular}{lc}
\hline Characteristic & All patients (n = 420) \\
\hline Age (years) & $42 \pm 12(18-65)$ \\
\hline Female & $288(68.6 \%)$ \\
\hline Education level & $30(7.1)$ \\
\hline Illiterate & $14(30.4)$ \\
\hline Primary education & \\
\hline Marital status & $288(68.6)$ \\
\hline Married & $95(22.6)$ \\
\hline Single & $37(8.8)$ \\
Divorced & \\
\hline Nodule location & $144(34.3)$ \\
\hline Housewife & $56(13.3)$ \\
Officer & $31(7.4)$ \\
Worker & $67(16.0)$ \\
Retired & $29(6.9)$ \\
Student & $26(6.2)$ \\
Not working & $67(16.0)$ \\
Self-employment/Private sector & \\
\hline Income rate & $158(37.6)$ \\
\hline Income less than expense & $210(50)$ \\
Equivalent to income expense & $52(12.4)$ \\
More than income &
\end{tabular}

Values are reported as mean \pm SD or percentage for categorical variables and median (IQR) for numeric variables

of the last week. It is a Likert-type self-assessment scale scoring between 0 and 3 and including 21 symptom categories. The highest possible score is 63 points.

A higher score indicates more severe depression. The Turkish validity and reliability of the Beck Depression scale was conducted by Hisli et al., and the cut-off score was accepted as 17 points. A score between 0 and 9 was evaluated as minimal depression, $10-16$ as mild depression, 17-29 as moderate depression, and 30-63 as severe depression [14].

\section{Statistical analysis}

To determine the sample size from the studies evaluating obesity, NES was found to be $19.4 \%$ in obese individuals and $5.7 \%$ in individuals with normal. OpenEpi sample size calculator was carried out with a predicting $95 \%$ confidence interval, $80 \%$ strength, $5 \%$ margin of error. A minimum of 105 patients per group was calculated to be required. Thus, the total sample size of less than 420 people was calculated. Statistical evaluation was performed using SPSS (Statistical Package for the Social Sciences; SPSS Inc., Chicago, Illinois, USA) 17.0 software. In the evaluation of the data obtained, continuous variables in the study are expressed as mean \pm standard deviation or median (minimum-maximum) values, and categorical variables are expressed as frequency and related percentage values. Whether the data such as age, Beck Depression Scale scores, and waist circumference showed normal distribution was evaluated with the Kolmogorov-Smirnov test. As a result of the Kolmogorov-Smirnov test, it was observed that the $\mathrm{p}$ value of the age parameter was 0.000 , the $p$ value of the Beck Depression Scale was 0.000 , and the $p$ value of the waist circumference was 0.02 . The Mann-Whitney U test was used for intergroup comparisons of these parameters. Comparison of categorical variables was 
made using the chi-square test or Fisher's exact chi-square test Relationships between continuous variables were analysed using Spearman correlation analysis. The significance level was based on a $\mathrm{p}$ value of less than 0.05

\section{Results}

A total of 420 participants were included in this research between January 2018 and May 2018. Of those 288 $(68 \%)$ were women, and their mean age was $42 \pm 13$ years. Table 1 presents a summary of the demographic characteristics of the participants. The mean body mass index (BMI) of the participants was $31.8 \pm 8.2$ (min: 18.5, max: 54.0).

Of those, $202(48 \%)$ had at least one chronic disease, including T2DM, HT, heart diseases, hypothyroidism, depression, and hyperlipidaemia. Among individuals with any chronic disease, T2DM was seen in 89 (21.2\%) persons, HT in $90(21.4 \%)$ persons, heart disease in 28 $(6.7 \%)$ persons, hypothyroidism in $44(10.5 \%)$ persons, depression in $27(6.4 \%)$ persons and hyperlipidemia in $59(14.0 \%)$ persons. Fifty-five $(13.1 \%)$ of the participants followed a diet, 86 (20.5\%) participants used alcohol regularly, $99(23.6 \%)$ individuals used to smoke regularly, and $47(11.2 \%)$ individuals were ex-smokers. Fifty-five $(13.1 \%)$ people had a regular diet.
When the persons included in the study were questioned in terms of whether there was a meal or snack during these time periods: 21:00-00:00, 00:00-03:00, 03:00-06:00 (after dinner), it was learned that $414(98.6 \%)$ people had eating habits in any of the specified time intervals, $336(80.0 \%)$ people were in the 21:00-00:00 period, $46(11.0 \%)$ were in the 00:00-03:00 period, and $7(1.7 \%)$ people were in the 03:00-06:00 period.

When the night eating questionnaire scores of the people included in the study were evaluated, the mean score was $15.2 \pm 6.7$. According to the total scores, 42 $(10 \%)$ participants had NES. The relationship between sociodemographic data and NES was evaluated, revealing that there was no correlation $(p>0.05)$

When the groups were divided according to NES, the aforementioned chronic diseases were more common in the group with NES; however, a statistically significant difference was found only in the diagnosis of depression $(\mathrm{p}<0.05)$.

When the relationship between smoking and NES was examined, it was observed that $16(16.2 \%)$ people who smoked had NES. It was determined that people who smoke have more NES than those who have never smoked, and a significant difference was found $(\mathrm{p}<0.05)$.

Table 2. Relationship between night eating syndrome (NES) and body mass index (BMI) group

\begin{tabular}{|c|c|c|c|c|c|c|c|}
\hline \multirow{2}{*}{ BMI group } & \multicolumn{2}{|c|}{ NES (+) } & \multicolumn{2}{|c|}{ NES (-) } & \multicolumn{2}{|c|}{ Total } & \multirow{2}{*}{$\mathrm{p}$ value } \\
\hline & $\mathbf{n}$ & $\%$ & $\mathbf{n}$ & $\%$ & $\mathbf{n}$ & $\%$ & \\
\hline Morbidly obese & 17 & 16.2 & 88 & 83.8 & 105 & 100 & \multirow{4}{*}{0.110} \\
\hline Obese & 9 & 8.6 & 96 & 91.4 & 105 & 100 & \\
\hline Overweight & 8 & 7.6 & 97 & 92.4 & 105 & 100 & \\
\hline Normal range & 8 & 7.6 & 97 & 92.4 & 105 & 100 & \\
\hline
\end{tabular}

Values are reported as mean \pm SD or percentage for categorical variables and median (IOR) for numeric variables

Table 3. Relationship between morbid obesity and night eating syndrome (NES)

\begin{tabular}{|c|c|c|c|c|c|c|c|}
\hline \multirow{2}{*}{ Group } & \multicolumn{2}{|c|}{ NES $(+)$} & \multicolumn{2}{|c|}{ NES (-) } & \multicolumn{2}{|c|}{ Total } & \multirow{2}{*}{ p value } \\
\hline & $\mathbf{n}$ & $\%$ & n & $\%$ & $\mathbf{n}$ & $\%$ & \\
\hline Morbidly obese & 17 & 16.2 & 88 & 83.8 & 105 & 100 & \multirow{2}{*}{0.015} \\
\hline Non-morbidly obese group & 25 & 7.9 & 290 & 92.1 & 315 & 100 & \\
\hline
\end{tabular}

Values are reported as mean \pm SD or percentage for categorical variables and median (IOR) for numeric variables

Table 4. Comparison of depression presence and night eating syndrome (NES) according to Beck Depression Inventory (BDI)

\begin{tabular}{|c|c|c|c|c|c|c|c|}
\hline \multirow{2}{*}{ Group } & \multicolumn{2}{|c|}{$\operatorname{NES}(+)$} & \multicolumn{2}{|c|}{ NES (-) } & \multicolumn{2}{|c|}{ Total } & \multirow{2}{*}{ p value } \\
\hline & $\mathbf{n}$ & $\%$ & $\mathbf{n}$ & $\%$ & $\mathbf{n}$ & $\%$ & \\
\hline Moderate-severe depression & 31 & 23.3 & 102 & 76.7 & 133 & 31.7 & \multirow{2}{*}{0.000} \\
\hline Minimal-mild depression & 11 & 3.8 & 276 & 96.2 & 287 & 68.3 & \\
\hline
\end{tabular}

Values are reported as mean $\pm S D$ or percentage for categorical variables and median (IOR) for numeric variables 
When the relationship between alcohol use and NES was examined, $34(10.2 \%)$ people who did not use alcohol had NES. Although there was more NES in people who used alcohol than those who did not use it, no significant difference was found ( $p>0.05$ ).

The BDI score levels of the patients in this study were divided into 4 groups: a) 0-9 points, minimal depression; b) 10-16, mild depression; c) 17-29, moderate depression; and d) 30-63, severe depression. On the other hand, taking into consideration the cut-off point of 17 , the patients were divided into 2 groups, one of which is minimal-mild depression and the other one is the moderate-severe depression. The mean BDI score was $23.5 \pm 10.86$ (min: 0, max: 46) in those with NES and $12.18 \pm 88.95$ (min: 0 , max: 49 ) in those without NES. A significant difference was found between the 2 groups in terms of BDI scores $(p<0.001)$

When the relationship of these groups with NES was examined, it was observed that $31(23.3 \%)$ people in the moderate-severe depression group had NES. The results revealed also that there was more NES in the moderate depression-severe depression group compared to the minimal depression-mild depression group, and a significant difference was found ( $p<0.001)$

The mean waist circumference was $102 \pm 20 \mathrm{~cm}$ in the group with NES and $95 \pm 18 \mathrm{~cm}$ in the group without NES. When the correlation between NES and waist circumference was evaluated, a low level of significant correlation was found in the same direction $(\mathrm{r}=0.145 ; \mathrm{p}<0.05)$.

When the relationship between BMI values and NES was examined, it was observed that $40 \%$ of people with NES had morbid obesity and $16.2 \%$ of people with morbid obesity had NES. A significant difference was found in patients with morbid obesity in terms of NES compared to those without morbid obesity $(p<0.001)$.

\section{Discussion}

NES was first investigated in obese patients, and the incidence of NES in obese patients is reported to be between $6 \%$ and $16 \%$ in studies conducted so far [5, 6]. In a study by Ozturk et al. with 290 participants with and without obesity, the frequency of NES was found to be $38.2 \%$ among all participants [15]. The high frequency of NES in the study of Ozturk et al. was explained by the fact that the people included in the study mostly lived close to the clinic where the study was conducted, that there were mostly textile companies in the area and that people work in shifts in these factories, and those who work with this system have more irregular eating hours [15]. In our study, the prevalence of NES was $10 \%$.

Although statistically not significant, we found more cases of NES in those who followed a diet. The higher frequency of NES in people who followed a diet can be explained by the fact that overweight people start diet therapy to lose weight, and these people have more NES, especially those who are obese or morbidly obese. Information regarding this comparison has not been observed in former studies.

Previous studies have reported that NES is more common in obese people compared to the general population [16, 17]. Ozturk et al. conducted a study on 290 participants and stated that the waist circumferences of $75.4 \%$ of men with NES was $\geq 94 \mathrm{~cm}$ and the waist circumference of $83.3 \%$ of women with NES was $\geq 80$ $\mathrm{cm}$, and argued that there was a strong relationship between waist circumference and NES for both genders. The waist circumference measurement value has been associated with NES in terms of its relation with obesity. Aronoff et al. and Colles et al. found a positive significant relationship between the increase in BMI and the presence of NES $[17,18]$. The researchers stated that the absence of this relationship in previous studies may be due to the investigation of NES in homogeneous populations and narrow weight ranges. Moreover, In the study conducted by Meule et al. with 2317 people, a positive significant relationship was found between the increase in BMI between the ages of 30 and 61 years and the presence of NES [19]. Stunkard et al. stated that NES can be seen in $8.9-15 \%$ of people with obesity and $7.9-42 \%$ of people with morbid obesity, and they established a positive relationship between the increase in BMI and the presence of NES [20].

In contrast to these studies, Striegel-Moore et al. reported that the relationship between BMI and NES is not significant and stated that BMI did not seem to be associated with NES [7], as a result of their studies consisting of 8250 people between the ages of 15 and 39 years.

Another study exploring the relationship of the night eating with BMI and obesity showed that night eating was more frequent in normal-weight subjects than the obese patients [8]. Again, in a study conducted by Striegel-Moore et al., no significant difference was found between black women with NES and black women without NES in terms of mean BMI and frequency of obesity [9].

In our study, according to BMI values, it was observed that obese and morbid obese people had more NES among the people we examined in 4 groups, and morbid obesity was found to be significantly higher in people with NES. It was observed that $12.38 \%$ of the 210 people with obesity and $16.20 \%$ of the 105 people with morbid obesity had NES.

In the current study, as in the literature, a significant positive difference was found. The fact that the applied studies were conducted with groups with different 
characteristics includes the difference of the results of the study. It was observed that the number of calories consumed by people with night eating habits, irregular eating habits, living in a more sedentary manner, and thus being more prone to gaining weight, support the increase in the frequency of NES with an increase in BMI.

When the studies conducted in the past are examined, among these diseases, only information related to T2DM and NES was found. In the study conducted by Allison et al. involving 845 diabetic patients living in 4 different residential areas (Birmingham, Houston, Minneapolis, and Philadelphia), it was reported that $3.8 \%$ of the patients had NES [22]

Although the characteristics of different populations vary in general, the lifestyle, eating habits, and adaptation to the follow-up and treatment of diseases of the people living in our country also differ compared to other countries. In our study, the NES was observed in $13.5 \%$ of patients with diabetes. This result was higher than the previously mentioned studies. The small sample size and the data coming from a more limited area may explain this situation. It can also be explained by other features. In the study, it was seen that $38 \%$ of the 42 people with NES smoked. Smoking was significantly higher in people with NES. Among the eating disorders studies conducted by Pisetsky et al. and Kendzor et al. it was stated that smoking is also common in eating disorders, such as alcohol-substance use $[23,24]$. When the studies investigating the relationship between NES and smoking were examined, it was stated that the patients used to smoke in addition to waking up from sleep in the sleep-related smoking syndrome studies performed by Provini et al. with 6 patients using video polysomnography [25].

In a large sample (2217 people) study, Lundgren et al. investigated the effect of eating at night on tooth loss in adults, and they found that smoking was significantly higher in those who ate meals at night. It was observed that people with night eating were determined by asking whether they woke up at night to eat as a single question, and no night eating questionnaire was applied. It was found that $51.4 \%$ of the 177 people who woke up to eat at night were smokers [10]The lower rate in our study can be explained by the sample size and population difference. Nicotine increases energy expenditure in the short term and can reduce appetite; however, it has been reported that in heavy smokers, lack of physical activity, inadequate diet, and smoking can lead to weight gain [26]. In addition, nicotine is reported to increase calorie intake during meals [27, 28]. Thus, it can be thought that smoking in people with NES may lead to a decrease in nutritional quality, an increase in weight gain and, consequently, an increase in night eating complaints.
It was seen that $78.57 \%$ of the people with NMS missed at least one of the mealtimes, and a significant difference was found. There is no study comparing the status of skipping meals with the presence of NES; however, in general studies, it was observed that nutritional irregularities were higher in people with NES compared to those without [29]. In this study, it was observed that breakfast or lunch were skipped by many people, especially lunch. It has been observed that people who do not sleep until late at night need to eat in the night time, thus consuming a significant part of their daily calorie consumption after dinner. Accordingly, they stated that they did not feel much hunger when they woke up in the morning, or they woke up around lunch time and skipped breakfast. It has been observed that people who try to diet on their own try to reduce the number and size of meals and disrupt their meal patterns. More NES in these people may explain the relationship between NES and nutritional meal irregularity.

\section{Conclusion}

In line with the results of this study, it was observed that morbid obesity, depression, and NES are closely related to each other.

\section{Conflict of interest}

The authors declare that they have no conflict of interest.

\section{Author contributions}

The study conception and design were contributed by G.P. G.P., C.S., and K.O. performed the material preparation, data collection, and analysis. G.P. and C.S. wrote the first draft of the manuscript, and all authors commented on previous versions of the manuscript.

\section{Data availability statement}

The data that support the findings of this study are available upon request from the corresponding author. The data are not publicly available due to privacy or ethical restrictions.

\section{References}

1. Hruby A, Hu FB. The Epidemiology of Obesity: A Big Picture. Pharmacoeconomics. 2015; 33(7): 673-689, doi: 10.1007/s40273-014-0243-x, indexed in Pubmed: 25471927.

2. Sach TH, Barton GR, Doherty M, et al. The relationship between body mass index and health-related quality of life: comparing the EQ-5D, EuroQol VAS and SF-6D. Int J Obes (Lond). 2007; 31(1): 189-196, doi: 10.1038/sj.ijo.0803365, indexed in Pubmed: 16682976.

3. Stunkard A, Berkowitz R, Wadden T, et al. Binge eating disorder and the night-eating syndrome. Int J Obes Relat Metab Disord. 1996; 20(1): 1-6, indexed in Pubmed: 8788315

4. Cerú-Björk C, Andersson I, Rössner S. Night eating and nocturnal eating-two different or similar syndromes among obese patients? Int J Obes Relat Metab Disord. 2001; 25(3): 365-372, doi: 10.1038/sj.ijo.0801552, indexed in Pubmed: 11319634 
5. Gluck ME, Geliebter A, Satov T. Night eating syndrome is associated with depression, low self-esteem, reduced daytime hunger, and less weight loss in obese outpatients. Obes Res. 2001; 9(4): 264-267, doi: 10.1038/oby.2001.31, indexed in Pubmed: 11331430.

6. Rand C, Macgregor A, Stunkard A. The night eating syndrome in the general population and among postoperative obesity surgery patients. Int J Eat Disord. 1997; 22(1): 65-69, doi: 10.1002/(sici)1098-10 8x(199707)22:1<65::aid-eat8>3.0.co;2-0, indexed in Pubmed: 9140737.

7. Striegel-Moore RH, Franko DL, Thompson D, et al. Night eating: prevalence and demographic correlates. Obesity (Silver Spring). 2006; 14(1): 139-147, doi: 10.1038/oby.2006.17, indexed in Pubmed: 16493132 .

8. Striegel-Moore RH, Dohm FA, Hook JM, et al. Night eating syndrome in young adult women: prevalence and correlates. Int J Eat Disord. 2005; 37(3): 200-206, doi: 10.1002/eat.20128, indexed in Pubmed: 15822078.

9. Lundgren JD, Williams KB, Heitmann BL. Nocturnal eating predicts tooth loss among adults: results from the Danish MONICA study. Eat Behav. 2010; 11(3): 170-174, doi: 10.1016/j.eatbeh.2010.02.003, indexed in Pubmed: 20434064.

10. Styne DM, Arslanian SA, Connor EL, et al. Clinical Guidelines on the Identification, Evaluation, and Treatment of Overweight and Obesity in Adults--The Evidence Report. National Institutes of Health. Obes Res. 1998; 6 Suppl 2(3): 51S-51209S, indexed in Pubmed: 9813653.

11. Allison $\mathrm{KC}$, Lundgren JD, O'Reardon JP, et al. The Night Eating Questionnaire (NEQ): psychometric properties of a measure of severity of the Night Eating Syndrome. Eat Behav. 2008; 9(1): 62-72, doi: 10.1016/j. eatbeh.2007.03.007, indexed in Pubmed: 18167324

12. Atasoy N, Saracli O, Konuk N, et al. The reliability and validity of Turkish version of The Night Eating Questionnaire in psychiatric outpatient population. Anatolian Journal of Psychiatry. 2014; 15(3): 238, doi: 10.5455/apd.39829.

13. Hisli N. Beck Depresyon Envanterinin üniversite öğrencileri için geçerliği, güvenirliği. Psikoloji Dergisi. 1989; 7: 3-13.

14. Öztürk G, Eğici M, ToprakD, et al. Relationship Between Night Eating Disorders and Obesity. Ankara Med Journal. 2018, doi: 10.17098/amj.409014.

15. Adami GF, Campostano A, Marinari GM, et al. Night eating in obesity: a descriptive study. Nutrition. 2002; 18(7-8): 587-589, doi: 10.1016/s0899-9007(02)00761-x, indexed in Pubmed: 12093435.

16. Aronoff NJ, Geliebter A, Zammit G. Gender and body mass index as related to the night-eating syndrome in obese outpatients. J Am Diet Assoc. 2001; 101(1): 102-104, doi: 10.1016/S0002-8223(01)00022-0, indexed in Pubmed: 11209573.

17. Colles SL, Dixon JB, O'Brien PE. Night eating syndrome and nocturnal snacking: association with obesity, binge eating and psychological distress. Int J Obes (Lond). 2007; 31(11): 1722-1730, doi: 10.1038/sj.ijo.0803664, indexed in Pubmed: 17579633.

18. Meule A, Allison $\mathrm{KC}$, Brähler E, et al. The association between night eating and body mass depends on age. Eat Behav. 2014; 15(4): 683-685, doi: 10.1016/j.eatbeh.2014.10.003, indexed in Pubmed: 25462027.

19. Stunkard AJ, Allison KC. Two forms of disordered eating in obesity: binge eating and night eating. Int J Obes Relat Metab Disord. 2003; 27(1): 1-12, doi: 10.1038/sj.ijo.0802186, indexed in Pubmed: 12532147.

20. Striegel-Moore RH, Franko DL, Thompson D, et al. Exploring the typology of night eating syndrome. Int J Eat Disord. 2008; 41(5): 411-418, doi: 10.1002/eat.20514, indexed in Pubmed: 18306340.

21. Çayır A, Atak N, Köse SK. Beslenme ve Diyet Kliniğine Başvuranlarda Obezite Durumu ve Etkili Faktörlerin Belirlenmesi. Ankara Üniversitesi Tıp Fakültesi Mecmuası. 2011; 64(1): 13-19, doi: 10.1501/tipfak_0000000779.

22. Pisetsky EM, Chao YM, Dierker LC, et al. Disordered eating and substance use in high-school students: results from the Youth Risk Behavior Surveillance System. Int J Eat Disord. 2008; 41(5): 464-470, doi: 10.1002/eat.20520, indexed in Pubmed: 18348283.

23. Kendzor DE, Adams CE, Stewart DW, et al. Cigarette smoking is associated with body shape concerns and bulimia symptoms among young adult females. Eat Behav. 2009; 10(1): 56-58, doi: 10.1016/j.eatbeh.2008.10.012, indexed in Pubmed: 19171320.

24. Provini F, Vetrugno R, Montagna P. Sleep-related smoking syndrome. Sleep Med. 2008; 9(8): 903-905, doi: 10.1016/j.sleep.2007.10.021, indexed in Pubmed: 18291719.

25. Chiolero A, Faeh D, Paccaud F, et al. Consequences of smoking for body weight, body fat distribution, and insulin resistance. Am J Clin Nutr. 2008 ; 87(4): 801-809, doi: 10.1093/ajcn/87.4.801, indexed in Pubmed: 18400700.

26. Perkins KA, Epstein LH, Stiller RL, et al. Acute effects of nicotine on hunger and caloric intake in smokers and nonsmokers. Psychopharmacology (Berl). 1991; 103(1): 103-109, doi: 10.1007/BF02244083, indexed in Pubmed: 2006236.

27. Perkins KA, Epstein LH, Sexton JE, et al. Effects of nicotine on hunger and eating in male and female smokers. Psychopharmacology (Berl). 1992; 106(1): 53-59, doi: 10.1007/BF02253588, indexed in Pubmed: 1738793.

28. Napolitano MA, Head S, Babyak MA, et al. Binge eating disorder and night eating syndrome: psychological and behavioral characteristics. Int J Eat Disord. 2001; 30(2): 193-203, doi: 10.1002/eat.1072, indexed in Pubmed: 11449453.

29. Allison KC, Grilo CM, Masheb RM, et al. Binge eating disorder and night eating syndrome: a comparative study of disordered eating. J Consult Clin Psychol. 2005; 73(6): 1107-1115, doi: 10.1037/0022-006X.73.6.1107, indexed in Pubmed: 16392984 